\title{
Inventory policy decision under an integrated vendor-buyer cooperative inventory model
}

\author{
Peng Zhang ${ }^{1, a^{*}}$, Jie $X u^{1, b}$ \\ ${ }^{1}$ School of Economics and Management, Southeast University, Nanjing 210096, China; \\ aaaazpzp@163.com, ${ }^{b} 596897886 @ q q . c o m$ \\ ${ }^{*}$ Corresponding author. Peng Zhang, aaazpzp@163.com
}

Keywords: Inventory model; Imperfect quality; Multiple screening; Inspection errors; Shortage backordering

\begin{abstract}
This paper mainly studies the optimal order size, the maximum shortage level and the optimal delivery times to maximize the total joint annual profits of inventory. To end this, we establish an inventory model which consists of a vendor and a buyer. For more close to the actual, we consider the several realities of situations, such as imperfect quality, multiple screening, inspection errors and shortage backordering. We then use the optimal theory to get the optimal decision of order size, the maximum shortage level and the optimal delivery times. Based on it, we also find two useful managerial insights. First, the vendor and the buyer do not need pay attention on changing order size and maximum shortage level when defective probabilities changes. Second, we propose a feasible method to find the specific delivery times. Finally, we further illustrate our finding by using numerical experiment.
\end{abstract}

\section{Introduction}

Integrated inventory management has recently enjoyed a great deal of attention. Many famous firms, such as P\&G, Wal-Mart, Campbell Soup, Johnson \& Johnson, have been attempting to achieve greater collaborative advantages with their supply chain partners in the past few decades. For example, P\&G and Wal-Mart have achieved a win-win plan through production and marketing alliance. Yao et al. (2010)[1]developed an inventory model under VMI pattern, in which a manufacturer may use an incentive contract to obtain market share, thereby lower inventory at the distributor being associated with a higher conversion rate of lost sales stock-outs to backorders. Cao and Zhang (2010)[2]showed us the supply chain collaborative advantages from a firm's perspective. More specifically, the supply chain collaborative advantages can be formulated from five aspects: process efficiency, offering flexibility, business synergy, quality and innovation. Hoque and Goyal (2000) [3] developed an optimal policy for the single-vendor single-buyer integrated production-inventory system under the capacity constraint of the transport equipment with both equal and unequal size from the vendor to the buyer. All these literatures indicate that the vendor and the buyer should work together in a cooperative manner towards maximizing their mutual benefits or minimizing their mutual costs.

Based on the above, many researches further consider some reality factors. Huang (2002)[4] and Hsu and Hsu (2012)[5]extended the integrated vendor-buyer inventory model by considering imperfect-quality items with equally sized shipment from the vendor to the buyer. Yoo et al. (2009) [6] suggested two inspection errors usually could be found in inspection process which meant an inspector could incorrectly classify a non-defective item to be defective (a Type I error) or incorrectly classify a defective item to be non-defective (a Type II error). Salameh and Jaber (2000)[7]took permissible shortage backordering and the effect of varying backordering cost values into consideration. Hsu and Hsu (2013) [8] and Tai (2013) [9] further consider lot size and the maximum shortage level. Krajewski 
et al. (2012) [10] discuss the method to get the optimal inventory police under considering these factors.

This paper makes at least two important contributions. First, almost all extant researches just consider either inspection errors in a single screening process or multiple screening processes with no screening errors. This paper applies the inspection errors (a Type I error and a Type II error) into the multiple screening processes. Second, almost all extant researches just consider rework the defective items from the screened out by the buyer. This paper further considers the returned items from consumers.

\section{Notation and assumptions}

We consider the inventory model with a single vendor and a single buyer. The following notations are used in our model.

$Q_{P}$ : The size of a production batch at the vendor, including the size of products made from raw materials, $Q_{M}$, and the size of products reworked from returned items, $Q_{R}\left(Q_{P}=Q_{M}+Q_{R}\right)$.

$Q$ : The size of the shipments from the vendor to the buyer, and $Q_{M}+Q_{R}=n Q$.

$D$ : Constant annual demand rate of units for buyer.

$B$ : The maximum backordering quantity in units at the buyer.

$P_{M}$ : The annual production rate because of processing raw materials at the vendor.

$P_{R}$ : The annual production rate because of reworking returned items at the vendor.

$S_{V}$ : The setup cost per production run for the vendor.

$S_{B}$ : The ordering cost per order for the buyer.

$p_{i}$ : The defective percentage of $S_{i}$ in $Q(i=1, \ldots, m)$.

$m_{1 i}\left(m_{2 i}\right)$ : The probability of a Type I (Type II) error.

$f\left(p_{i}\right), f\left(m_{1 i}\right), f\left(m_{2 i}\right)$ : the probability density function.

$B_{1}$ : The number of items that are classified as defective in each lot.

$B_{2}$ : The number of defective items that are returned from consumers in each lot.

$B_{T}$ : The number of defective items returned from the buyer in each lot, $B_{T}=B_{1}+B_{2}$.

$c_{a}, c_{r}, c$ and $c_{M}$ : Respectively show the cost of accepting a defective item, the cost of rejecting a non-defective item, The unit variable cost paid by the buyer, and The unit production cost because of using raw materials, $c_{M}<c$.

$s$ : The unit selling price of a non-defective item.

$v$ : The vendor's unit warranty cost per defective item for the buyer, $v<c$.

$d_{i}$ : The unit screening cost of $S_{i}(i=1, \ldots, m)$.

$b:$ The backordering cost per unit per unit time.

$h_{\mathbf{B}}$ : The holding cost for items per unit per unit time at the buyer's place.

$h_{V}$ : The holding cost for new products at the vendor's place, for returned defective items is $\phi h_{V}$.

$F:$ The freight transportation cost per delivery from the vendor to the buyer.

$T, T_{1}, T_{2}$ and $T_{c}$ : Respectively denote Time interval between successive deliveries of Q units, Period during which the vendor produces new products made from raw materials, Period during which the vendor supplies from inventory which comes from raw materials, and Cycle time $T_{c}=T_{1}+T_{2}=n T$. 


\section{Inventory policy decision}

In this section, we mainly derive the optimal order size, the maximum shortage level and the optimal delivery times to maximize the total joint annual profits generated by the vendor and the buyer. To end this, we first study the optimal order size and the maximum shortage level, and get the following proposition.

The expected annual profit is

$$
\begin{aligned}
& \operatorname{ETPU}(n, Q, B) \\
& =\frac{D}{1-E[\rho]}\left\{s E[\alpha]+\frac{h_{B}(1-E[\rho]) B}{D}-\left(\begin{array}{l}
\left.c_{a}(1-E[\rho]-E[\alpha])+c_{M} E[\alpha]\right) \\
+E[d]+c_{r}(E[u]-E[\alpha])
\end{array}\right)\right\} \\
& -\frac{D\left[S_{B}+S_{V}+n\left(F+\frac{\left(b+h_{B}\right) B^{2}}{2 D}\right)\right]}{n(1-E[\rho]) Q}-\frac{h_{B}(2-2 E[\rho]-E[\alpha]+E[\rho \alpha])}{2(1-E[\rho])} Q \\
& -\frac{D h_{V}}{1-E[\rho]}\left\{\begin{array}{l}
\frac{(1-\phi)\left(1-2 E[\alpha]+E\left[\alpha^{2}\right]\right)}{2 P_{R}}+\frac{\phi(1-E[\rho]-E[\alpha]+E[\rho \alpha])}{D} \\
+\frac{(2-n) E\left[\alpha^{2}\right]}{2 P_{M}}+\frac{(n-1)(E[\alpha]-E[\rho \alpha])}{2 D}
\end{array}\right\} Q
\end{aligned}
$$

Where

$$
\alpha=\prod_{i=1}^{m} \alpha_{i}, u=\prod_{i=1}^{m}\left(1-p_{i}\right), \rho=\sum_{i=1}^{m} \rho_{i}, \text { and } E[d]=\sum_{i=1}^{m} d_{i}-\sum_{i=1}^{m-1}\left(E\left[\rho_{i}\right] \cdot \sum_{k=i+1}^{m} d_{k}\right)
$$

Proposition1. $\operatorname{ETPU}(n, Q, B)$ is jointly concave in $(Q, B)$ and the optimal $Q$ and $B$ have the following expressions:

$$
\begin{aligned}
& Q^{*}(n)=\sqrt{\frac{2\left(b+h_{B}\right) D\left[S_{B}+S_{V}+n F\right]}{n\left[2\left(b+h_{B}\right) A_{1}-h_{B}^{2}(1-E[\rho])^{2}\right]}} \\
& B^{*}(n)=\frac{h_{B}(1-E[\rho])}{b+h_{B}} Q^{*}(n)
\end{aligned}
$$

Where

$$
\begin{aligned}
A_{1}= & \frac{h_{B}(2-2 E[\rho]-E[\alpha]+E[\rho \alpha])}{2}+h_{V}\left\{\frac{(1-\phi) D\left(1-2 E[\alpha]+E\left[\alpha^{2}\right]\right)}{2 P_{R}}\right. \\
& \left.+\phi(1-E[\rho]-E[\alpha]+E[\rho \alpha])+\frac{(2-n) D E\left[\alpha^{2}\right]}{2 P_{M}}+\frac{(n-1)(E[\alpha]-E[\rho \alpha])}{2}\right\}
\end{aligned}
$$

From the proposition 1, we can find that that the optimal values of $Q$ and $B$ are independent of the costs of Type I and Type II errors. However, the optimal values of the decision variables are functions of the defective probabilities and Type I and Type II errors. This scenario implies that when the vendor and the buyer improve their technologies and their staff's quality to reduce the defective probabilities and Type I and Type II errors, they do not need to change their original marketing and operational strategy. We next discuss the optimal delivery times.

Proposition 2. The total integrated annual profit $\operatorname{ETPU}(n, Q, B)$ is a concave function of $n$.

From Proposition 2, we have the following Proposition.

Proposition 3. When $n^{*}$ is a positive integer, ETPU $\left(n^{*}, Q^{*}\left(n^{*}\right), B^{*}\left(n^{*}\right)\right)$ is the optimal value of $\operatorname{ETPU}(n, Q, B)$.However, if it is not an integer, $M$ is the optimal value of $\operatorname{ETPU}(n, Q, B)$, where $M$ denotes 


$$
M=\max \left\{\begin{array}{l}
\operatorname{ETPU}\left(\left[n^{*}\right]-1, Q^{*}\left(\left[n^{*}\right]-1\right), B^{*}\left(\left[n^{*}\right]-1\right)\right) \\
\operatorname{ETPU}\left(\left[n^{*}\right]+1, Q^{*}\left(\left[n^{*}\right]+1\right), B^{*}\left(\left[n^{*}\right]+1\right)\right)
\end{array}\right\}
$$

The key point is to determine the value of $n$ that maximizes $\operatorname{ETPU}(n, Q, B)$. Since $\operatorname{ETPU}(n, Q, B)$ is a complicated function of $n$, it is very difficult to get the analytical solution. What's more, $n$ is a series of discrete positive integer. Consequently, we can obtain the optimal $n$ by using the following way. Substituting $Q^{*}(n)$ and $B^{*}(n)$ into the expression of $\operatorname{ETPU}(n, Q(n), B(n))$, we get the expression of $\operatorname{ETPU}\left(n, Q^{*}(n), B^{*}(n)\right)$. If we find a $n$ is subject to the following two inequalities (5) and (6), that means we have obtain the optimal $n^{*}$.

$$
\begin{aligned}
& \operatorname{ETPU}\left(n, Q^{*}(n), B^{*}(n)\right) \geq \operatorname{ETPU}\left(n+1, Q^{*}(n+1), B^{*}(n+1)\right) \\
& \operatorname{ETPU}\left(n, Q^{*}(n), B^{*}(n)\right) \geq \operatorname{ETPU}\left(n+1, Q^{*}(n+1), B^{*}(n+1)\right)
\end{aligned}
$$

At this time, we can get the optimal amount of new products both by manufacturing the raw materials and by reworking the returned items, respectively given by $Q_{M}{ }^{*}=E[\alpha] n^{*} Q^{*}$ and $Q_{R}^{*}=(1-E[\alpha]) n^{*} Q^{*}$.

\section{Numerical experiments}

In this section, we suppose that there are five types of screening processes, $S_{i}(i=1, \ldots, 5)$. The values of the exogenous parameters have been shown in Tables 1 and 2.

Table 1 Values of the exogenous parameters

\begin{tabular}{cccccccc}
\hline$P_{M}$ & $P_{R}$ & $D$ & $c_{M}$ & $c_{a}$ & $c_{r}$ & $c$ & $v$ \\
\hline 160000 & 200000 & 50000 & 15 & 500 & 100 & 30 & 28 \\
$s$ & $b$ & $h_{B}$ & $h_{V}$ & $\phi$ & $F$ & $S_{B}$ & $S_{V}$ \\
50 & 10 & 7 & 5 & 0.6 & 25 & 100 & 300 \\
\hline
\end{tabular}

Table 2 Parameters for the screening processes $S_{i}(i=1, \ldots, 5)$

\begin{tabular}{cccccc}
\hline & $S_{1}$ & $S_{2}$ & $S_{3}$ & $S_{4}$ & $S_{5}$ \\
\hline$\beta_{i}$ & 0.04 & 0.02 & 0.08 & 0.06 & 0.1 \\
$\lambda_{i}$ & 0.06 & 0.04 & 0.07 & 0.03 & 0.05 \\
$\gamma_{i}$ & 0.02 & 0.01 & 0.03 & 0.06 & 0.04 \\
$d_{i}$ & 0.5 & 0.6 & 0.4 & 0.8 & 0.3 \\
\hline
\end{tabular}

The corresponding defective percentage and inspection errors are assumed to follow a uniform distribution. Specifically, we have

$$
f_{p_{i}}\left(p_{i}\right)=\left\{\begin{array}{c}
\frac{1}{\beta_{i}}, 0<p_{i}<\beta_{i} \\
0, \text { otherwise }
\end{array}, f_{m_{1 i}}\left(m_{1 i}\right)=\left\{\begin{array}{c}
\frac{1}{\lambda_{i}}, 0<m_{1 i}<\lambda_{i} \\
0, \text { otherwise }
\end{array}, \text { and } f_{m_{2 i}}\left(m_{2 i}\right)=\left\{\begin{array}{c}
\frac{1}{\gamma_{i}}, 0<m_{2 i}<\gamma_{i} \\
0, \text { otherwise }
\end{array}\right.\right.\right.
$$

According to the above values of exogenous parameters, we obtain a three-dimensional graph shown in Fig.1 $(n=6)$. The graph shows that the integrated total profit per year, $\operatorname{ETPU}(n, Q(n), B(n))$, is jointly concave, and there exists unique solutions of $Q$ and $B$ that maximize the expected annual profit. 


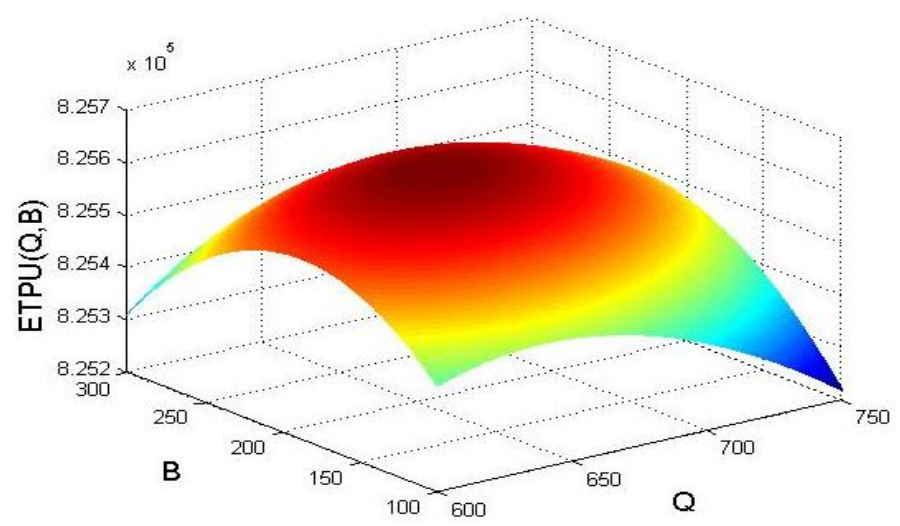

Figure. 1 The total expected annual profit for the integrated Vendor-Buyer inventory model.

\section{Conclusions}

In this paper, we develop an integrated vendor-buyer inventory policy for items with imperfect quality, multiple screening, inspection errors and shortage backordering. We mainly get the optimal order size, the maximum shortage level and the optimal delivery times. We also find two useful managerial insights. First, the vendor and the buyer do not need pay attention on changing order size and maximum shortage level when defective probabilities changes. Second, we propose a feasible method to find the specific delivery times.

Two possible extensions of this work can be adopted. Firstly, instead of considering the screening work at the buyer's place, we can consider having the vendor inspect the items and deliver the detected good-quality items to the buyer. Secondly, an item could be divided into good, rework or scrap and only the rework item can be refurbished.

\section{References}

[1] Y. Yao, Y. Dong, M. Dresner, Managing supply chain backorders under vendor managed inventory: An incentive approach and empirical analysis, European Journal of Operational Research, Vol. 203 (2010) No.2, p.350-359.

[2] M. Cao, Q. Zhang, Supply chain collaborative advantage: A firm's perspective. International Journal of Production Economics, Vol. 128 (2010) No.1, p.358-367.

[3] M.A. Hoque, S.K. Goyal, An optimal policy for a single-vendor single-buyer integrated production-inventory system with capacity constraint of the transport equipment, International Journal of Production Economics, Vol. 65 (2000) No.3, p.305-315.

[4] C.K. Huang, An integrated vendor-buyer cooperative inventory model for items with imperfect quality, Production Planning \& Control, Vol. 13 (2002) No.4, p.355-361.

[5] J.T. Hsu, L.F. Hsu, An integrated vendor-buyer cooperative inventory model for items with imperfect quality and shortage backordering, Advances in Decision Sciences, Vol. 2012 (2012), p.1-19.

[6] S.H. Yoo, D.S. Kim, M.S. Park, Economic production quantity model with imperfect-quality items, two-way imperfect inspection and sales return, International Journal of Production Economics, Vol. 121 (2009) No.1, p.255-265.

[7] M.K. Salameh, M.Y, Jaber, Economic production quantity model for items with imperfect quality, International Journal of Production Economics, Vol. 64 (2000) No.1, p.59-64. 
[8] J.T. Hsu, L.F. Hsu, An EOQ model with imperfect quality items, inspection errors, shortage backordering, and sales returns, International Journal of Production Economics, Vol. 143 (2013) No.1, p.162-170.

[9] A.H. Tai, An EOQ model for imperfect quality items with multiple screening and shortage backordering. arXiv preprint arXiv:1302.1323, 2013.

[10]L.J. Krajewski, L.P. Ritzman, M.K. Malhotra, Operations management (Pearson Education Limited), 2012. 